\title{
Violência de gênero - Feminicídio
}

\author{
Gender violence - Femicide
}

\author{
Cleudemir Malheiros Brito Filho \\ União das Faculdades dos Grandes Lagos, \\ UNILAGO - São José do Rio Preto/SP. Brasil.
}

Resumo Existe uma polêmica muito grande sobre o fundamento e a natureza dos direitos humanos, alguns os reconhecendo como direitos naturais, portanto, inatos, outros os entendendo como direitos positivos, alguns ainda os vendo como direitos históricos. Certo é que os direitos humanos, hodiernamente, são universais, cabendo, antes de qualquer coisa, efetivá-los e protegê-los. É evidente que, quando se fala de direitos humanos, estamos abarcando os direitos dos homens e das mulheres, mas, aqui, faremos uma análise mais específica das necessidades das mulheres, pois, sem dúvida nenhuma, há sérios problemas a serem enfrentados para que a mulher tenha seus direitos respeitados. Sob a ótica de uma necessária e diferenciada proteção à mulher, em 9 de março de 2015, fruto do Projeto de Lei do Senado $n^{\circ}$. 8.305/2014, foi publicada a Lei $\mathrm{n}^{\circ}$. 13.104, que criou, como modalidade de homicídio qualificado, o chamado feminicídio, que ocorre quando uma mulher vem a ser vítima de homicídio simplesmente por razões de sua condição de sexo feminino.

Palavras-chave: Direitos Humanos. Proteção À mulher. Feminicídio.

Abstract There is a big controversy about the basis and nature of human rights, some of them recognized as natural rights, therefore innate, others understand them as positive rights, some even seeing them as historical rights. It is true that human rights today are universal fitting, be- 
fore anything, actualize them and protect them. Clearly, when it comes to human rights, we are covering the rights of men and women, but here we will make a more specific analysis of women's needs because, undoubtedly, there are serious problems to be addressed to the women have their rights respected. From the perspective of a necessary and differentiated protection to women on March 9, 2015, the result of Senate Bill $n^{\circ} .8 .305 / 2014$ was issued Law $n^{\circ}$. 13.104, which created as aggravated homicide mode, called femicide, which occurs when a woman becomes a victim of homicide simply for the sake of their female condition.

Key-words: Human rights. Protection of women. Femicide.

\section{INTRODUÇÃO}

Ao discorrer sobre os direitos da mulher, dentro do núcleo direitos humanos, estamos diante de um tema de elevada importância. Cuida-se de zelar pela integração e participação das mulheres, não apenas como agentes, mas também como destinatárias do processo de desenvolvimento.

Se fundamental o reconhecimento de todos e cada ser humano, enquanto cidadão, sujeito de direitos e deveres, se fundamental a liberdade de expressão, o direito de votar e de ser eleito, que são, dentre outros, direitos civis e políticos, esses se revelaram insuficientes e nova geração se impôs: a dos direitos econômicos e sociais. O cidadão, pessoa concreta, precisa alimentar-se, educar-se e contar com determinadas e efetivas condições materiais para uma vida digna. Mas esses direitos também se revelaram insuficientes, pois a sociedade é mais do que a soma de indivíduos, ela é composta de indivíduos e grupos que dialogam e se interpenetram. Há de se reconhecer, portanto, o direito desses grupos. Daí o surgimento dos Direitos Coletivos, o que representou o reconhecimento de direitos fundamentais de grupos tais como os sindicatos de trabalhadores, entidades de deficientes, indígenas, de negros, homossexuais e es- 
pecificamente os vários grupos de mulheres, com suas demandas e pressões (PIMENTEL, 2016, p. 190).

O papel social da mulher e a sua posição na sociedade ainda são permeados de contradições. Entretanto, convém destacar que as mulheres desempenham uma função crucial na sociedade, sob a égide da desconstrução do patriarcalismo, na qual o homem sempre ocupou o espaço público e a mulher, o privado.

Em 1975, início do período que foi considerado a década da mulher, promovida pela ONU, as instituições e os órgãos responsáveis pelo estudo e aplicação dos assuntos relativos aos direitos humanos foram bastante criticados, pois os interesses e os problemas da mulher estavam sendo esquecidos e, até mesmo, graves violações à dignidade da mulher não eram levadas em consideração.

A partir da Declaração Universal de 1948, começa a se desenvolver o Direito Internacional dos Direitos Humanos, mediante a adoção de inúmeros tratados internacionais voltados à proteção dos direitos humanos, no âmbito das Nações Unidas.

Esse sistema normativo, por sua vez, é integrado por instrumentos de alcance geral (como os Pactos Internacionais de Direitos Civis e Políticos e de Direitos Econômicos, Sociais e Culturais de 1966) e por instrumentos de alcance específico, como as Convenções Internacionais que buscam responder a determinadas violações de direitos humanos, como a tortura, a discriminação racial, a discriminação contra a mulher, a violação dos direitos da criança, dentre outras formas de violação.

Firma-se, assim, no âmbito do sistema global, a coexistência dos sistemas geral e especial de proteção dos direitos humanos, como sistemas de proteção complementares.

O sistema especial de proteção realça o processo de especificação do sujeito de direito, no qual o sujeito passa a ser visto em sua especificidade e concreticidade (ex.: 
protegem-se as mulheres, as crianças, os grupos étnicos minoritários, as vítimas de tortura etc.). Já o sistema geral de proteção (ex.: Pacto da ONU de 1966) tem por endereçado toda e qualquer pessoa, concebida em sua abstração e generalidade.

Com o processo de especificação do sujeito de direito, mostra-se insuficiente tratar o indivíduo de forma genérica, geral e abstrata. Torna-se necessária a especificação do sujeito de direito, que passa a ser visto em suas peculiaridades e particularidades. Nessa ótica, determinados sujeitos de direitos, ou determinadas violações de direitos, exigem uma resposta específica, diferenciada. Nesse sentido, as mulheres devem ser vistas nas especificidades e peculiaridades de sua condição social. Importa o respeito à diferença e à diversidade, o que lhes assegura um tratamento especial (PIOVESAN, 2016, p. 191).

É fato que os principais documentos internacionais de tutela dos direitos humanos de há muito anunciam a igualdade de todos. Não obstante, tal igualdade tem se conservado meramente formal, sendo custosa a tarefa de transformá-la em igualdade real entre mulheres e homens, principalmente quando se verifica que a construção histórica dos direitos humanos sempre ocorreu com a exclusão da mulher e o reforço de ideologias machistas.

Em 1979, as Nações Unidas aprovaram a "Convenção sobre a Eliminação de Todas as Formas de Discriminação Contra a Mulher”, ratificada pelo Brasil em 1984 e, hoje, por 109 países.

Fazendo uma breve incursão, pode-se retroceder a um dos primeiros documentos históricos de proteção de direitos humanos, oriundo da Revolução Francesa (Declaração dos Direitos do Homem e do Cidadão de 1789), que nos reporta, como já mencionado, à história de Olimpe de Gouges, escritora que morreu guilhotinada em 3 de novembro de 1793 por ousar desejar igualdade política para mulheres e homens em sua célebre Déclaration des droitis de la Femme e de la citoyanne (LAGARDE, 2006, p. 216). 
A Convenção Interamericana foi aprovada pela Assembleia Geral da Organização dos Estados Americanos, em 9 de junho de 1994, e ratificada pelo Brasil em 27 de novembro de 1995.

Essa Convenção tem como fundamentos eliminar a discriminação e assegurar igualdade.

Para a Convenção, discriminação contra a mulher significa "toda distinção, exclusão ou restrição baseada no sexo e que tenha por objeto ou resultado prejudicar ou anular o reconhecimento, gozo, exercício pela mulher, independentemente de seu estado civil, com base na igualdade do homem e da mulher, dos direitos humanos e das liberdades fundamentais nos campos político, econômico, social, cultural e civil ou em qualquer outro campo" (art. $1^{\circ}$.).

A discriminação da mulher viola os princípios de igualdade de direitos e respeito à dignidade humana, constitui um obstáculo para $\mathrm{o}$ aumento do bem-estar da sociedade e da família e entorpece o pleno desenvolvimento das possibilidades da mulher para prestar serviços ao seu país e à humanidade.

Cuida-se de dois princípios fundamentais dentro de uma categoria dogmática analítica, empírica e normativa.

A perspectiva analítico-dogmática, preocupada com a construção sistemático-conceitual do direito positivo, é indispensável ao aprofundamento e análise de conceito fundamentais, à iluminação das construções jurídico-constitucionais e à investigação da estrutura do sistema jurídico e das suas relações com os direitos fundamentais, passando pela própria ponderação de bens jurídicos, sob a perspectiva dos direitos fundamentais. A perspectiva empírico-dogmática interessa de acordo com os direitos fundamentais, para terem verdadeira força normativa, obrigam a tomar em conta as suas condições de eficácia e o modo como o legislador, juízes e administração os observam e aplicam nos vários contextos práticos. A perspectiva normativo-dogmática é importante, sobretudo em sede de aplicação dos direitos fundamentais, dado que esta pressupõe, sempre, a fundamentação racional e jurídico-normativa dos juízos de valor (CANOTILHO, 2007, p. 393).

A conjugação dessas três dimensões iluminará a natureza praxe-lógica do direito constitucional no âmbito dos direitos fundamentais, 
isto é, o rigor dogmático vai fornecer-nos instrumentos de trabalho para a compreensão do regime jurídico dos direitos fundamentais.

A igualdade de homens e mulheres está consubstanciada na norma geral da igualdade perante a lei. Já está também contemplada em todas as normas constitucionais que vedam discriminação de sexo. Mas não é sem consequência que o Constituinte decidiu destacar, em um inciso específico, que "homens e mulheres são iguais em direitos e obrigações, nos termos desta Constituição". Era dispensável acrescentar a cláusula final, porque, ao estabelecer a norma, por si, já estava dito que seria "nos termos desta Constituição". Isso é de somenos importância. Importa mesmo é notar que é uma regra que resume décadas de lutas das mulheres contra discriminações. Mais relevante ainda é que não se trata aí de mera isonomia formal. Não é igualdade perante a lei, mas igualdade em direitos e obrigações. Significa que existem dois termos concretos de comparação: homens de um lado e mulheres de outro. Onde houver um homem e uma mulher, qualquer tratamento desigual entre eles, a propósito de situações pertinentes a ambos os sexos, constituirá uma violação constitucional.

O princípio da dignidade humana é uma das principais bases do Estado Democrático de Direito, servindo de horizonte para todas as áreas do Direito.

Entre os Direitos Humanos sempre existiu uma problemática doutrinária acerca daquele que seria, de fato, o ponto central, o direito indispensável, o princípio absoluto do universo jurídico, o princípio dos princípios ou o princípio máximo, ao qual todos os demais deveriam curvar-se em sua compreensão e aplicação. Cuidaria de apontar o princípio a prevalecer no caso de combate com outros princípios ou direitos, tendo em vista a sua imprescindibilidade primeira (MARTINS, 2005, p. 198).

A Convenção Interamericana para Prevenir, Punir e Erradicar a Violência contra a Mulher determina, portanto, a erradicação de toda discriminação contra as mulheres, para garantir-lhes o pleno exercício de seus direitos civis, políticos, sociais, econômicos e culturais. Estabelece a Declaração Universal em relação direta com a indivisibilidade dos direitos humanos. 
Na esteira das determinações contidas na aludida Convenção, em 7 de agosto de 2006 foi publicada a Lei ${ }^{\circ}$. 11.340, que cria mecanismos para coibir a violência doméstica e familiar contra a mulher, nos termos do $\S 8^{\circ}$. do art. 226 da Constituição Federal, da Convenção sobre a Eliminação de Todas as Formas de Discriminação contra as Mulheres e da Convenção Interamericana para Prevenir, Punir e Erradicar a Violência contra a Mulher; dispõe sobre a criação dos Juizados de Violência Doméstica e Familiar contra a Mulher; altera o Código de Processo Penal, o Código Penal e a Lei de Execução Penal; e dá outras providências.

Ao mesmo tempo em que não se consegue tornar-se de maneira expressiva e isonômica espaços institucionais dos entes do Estado, ainda carece-se da intervenção desse mesmo Estado para o processo de enfrentamento às violências cotidianamente vividas.

Acima de tudo, é fundamental esclarecer que a referida lei estrutura-se sobre a dimensão do gênero, conferindo um significado cultural à prática da violência e desnaturalizando, por conseguinte, pressuposições de que a prática de tal fenômeno seja justificável por razões como o destempero emocional, o temperamento agressivo, o excesso de força física, ou ainda pelo consumo de álcool ou drogas, muito embora não se deixe de reconhecer que tais fatores podem se somar às dinâmicas culturais que ditam os comportamentos violentos.

Vulgarmente conhecida como "Lei Maria da Penha", ela estabelece que todo o caso de violência doméstica e intrafamiliar é crime, e deve ser apurado por meio de inquérito policial e ser remetido ao Ministério Público. Esses crimes são julgados nos Juizados Especializados de Violência Doméstica contra a Mulher, criados a partir dessa legislação, ou, nas cidades em que ainda não existem, nas Varas Criminais.

A lei também tipifica as situações de violência doméstica, próibe a aplicação de penas pecuniárias aos agressores, amplia a pena de um para até três anos de prisão e determina o encaminhamento das mulheres em situação de violência, assim como de seus dependentes, a programas e serviços de proteção e de assistência social. A Lei nº 11.340 passou a ser chamada Lei Maria da Penha em homenagem à mulher 
cujo marido tentou matá-la duas vezes e que desde então se dedica à causa do combate à violência contra as mulheres.

O texto legal foi resultado de um longo processo de discussão a partir de proposta elaborada por um conjunto de ONGs (Advocacy, Agende, Cepia, Cfemea, Claden/IPÊ e Themis). Essa proposta foi discutida e reformulada por um grupo de trabalho interministerial, coordenado pela Secretaria Especial de Políticas para as Mulheres (SPM), e enviada pelo Governo Federal ao Congresso Nacional.

Em 9 de março de 2015, indo mais adiante, fruto do Projeto de Lei do Senado $n^{\circ}$. 8.305/2014, foi publicada a Lei $\mathrm{n}^{\circ}$. 13.104, que criou, como modalidade de homicídio qualificado, o chamado feminicídio, que ocorre quando uma mulher vem a ser vítima de homicídio simplesmente por razões de sua condição de sexo feminino.

\section{ConCEito de FeMicídio/Feminicídio}

A expressão femicídio - ou femicide como formulada originalmente em inglês - é atribuída a Diana Russel, que a teria utilizado pela primeira vez em 1976, durante um depoimento perante o Tribunal Internacional de Crimes contra Mulheres, em Bruxelas (CAPUTI; RUSSEL, 1992, p. 34, traduzido).

Russel utilizou essa expressão para designar os assassinatos de mulheres que teriam sido provocados pelo fato de serem mulheres. Com essa primeira aproximação sobre o significado dessas mortes, Diana Russel salienta que as mortes classificadas como femicídio resultariam de uma discriminação baseada no gênero, não sendo identificadas conexões com outros marcadores de diferença tais como raça/etnia ou geração. Ainda, segundo Diana Russel, outra peculiaridade que define femicídio é não ser um fato isolado na vida das mulheres vitimizadas, mas apresentar-se como o ponto final em uma sequência de terror, que inclui abusos verbais e físicos e uma extensa gama de manifestações de violência e privações a que as mulheres são submetidas ao longo de suas vidas. Sempre que esses abusos resultam na morte da mulher, eles devem ser identificados como femicídio (CAPUTI; RUSSEL, 1992, p. 35, traduzido). 
A ciência que fornece informação válida, confiável e contrastada sobre esse problema criminal, através do método empírico (observação da realidade), é a Criminologia. Não se trata de uma arte, ou de uma práxis, mas de uma autêntica ciência. Irrefutavelmente por isso, a Criminologia dispõe de objeto de conhecimento próprio, de método e de sólido corpo de doutrina a respeito do fenômeno delitivo, avaliado por mais de um século de investigações (GARCÍA-PABLOS DE MOLINA, 2013, p. 15, traduzido).

Todavia, isso não significa que a informação subministrada pela Criminologia deva reputar-se exata, concludente ou definitiva. Pois a Criminologia é uma ciência empírica, uma ciência do ser, mas não uma ciência exata.

A pessoa do delinquente alcançou seu máximo protagonismo como objeto das investigações criminológicas durante a etapa positivista. O princípio da diversidade que inspirou a Criminologia tradicional (o delinquente como realidade biopsicopatológica) o converteu no centro quase exclusivo da atenção científica (GARCÍA-PABLOS DE MOLINA, 2013, p. 16, traduzido).

Na moderna Criminologia, no entanto, o estudo do homem delinquente passou a segundo plano, como consequência do giro sociológico experimentado por ela e da necessária superação de enfoques individualistas em atenção a objetivos político-criminais. $\mathrm{O}$ centro de interesse das investigações - ainda que sem nunca abandonar a pessoa do infrator - desloca-se prioritariamente para a própria conduta delitiva, a vítima e o controle social. Em todo caso, examina-se o delinquente "em suas interdependências sociais", como unidade biopsicossocial, e não de uma perspectiva biopsicopatológica (GARCÍA-PABLOS DE MOLINA, 2013, p. 20, traduzido).

As nomenclaturas femicídio e feminicídio, embora sejam utilizadas indistintamente na América Latina, referem-se aos assassinatos sexuais de mulheres e, por conseguinte, diferenciam-se do neutral homicídio. Porém, algumas correntes sustentam que o termo femicídio não dá conta da complexidade nem da gravidade dos delitos contra a vida das mulheres por sua condição de gênero, pois etimologicamente signi- 
fica unicamente dar morte a uma mulher. A expressão feminicídio, por sua vez, abarcaria a motivação pautada no gênero ou misoginia, agregando a inação estatal frente aos crimes (PATH, 2010, p. 30).

Marcela y de los Ríos Lagarde (LAGARDE, 2006, p. 221), responsável pela introdução do termo "feminicídio" na academia, tem optado por ele por incluir o fator impunidade, em virtude de ausências legais e de políticas do governo, que geram uma convivência insegura para as mulheres, colocando-as em risco e favorecendo o conjunto de crimes praticados por razões de gênero. Segundo Lagarde, o feminicídio não é apenas uma violência exercida por homens contra mulheres, mas por homens em posição de supremacia social, sexual, jurídica, econômica, política, ideológica e de todo tipo, sobre mulheres em condições de desigualdade, de subordinação, de exploração ou de opressão, e com a particularidade da exclusão (LAGARDE, 2006, p. 221).

Sucintamente, o femicídio/feminicídio decorre de condições socioculturais históricas, que geram e permitem práticas atentatórias contra a vida, a saúde, a integridade, a dignidade e a liberdade da mulher, para as quais contribuem não somente os autores da sociedade (família, matrimônio, comunidade), mas também o Estado, por meio de sua omissão, ineficácia, negligência na prevenção, deficiência na investigação, ausência de repressão e de um quadro legal e político de governo, que favoreça a visibilidade da violência contra as mulheres e o fim da impunidade, do silêncio e da indiferença social.

\section{LEI No 13.104 - FEMINICÍDIO}

A Lei $n^{\circ} .13 .104$ alterou o Código Penal, criando o feminicídio como um tipo de homicídio qualificado, e o incluiu no rol dos crimes hediondos. Os homicídios qualificados têm pena que vão de 12 a 30 anos de reclusão, enquanto os homicídios simples preveem reclusão de 6 a 20 anos.

Os crimes hediondos, por sua vez, são aqueles arraigados de extrema gravidade e que, por isso, recebem um tratamento mais severo por parte da justiça. Eles são inafiançáveis e não podem ter a pena reduzida. 
A lei pontua também algumas situações agravantes, que podem aumentar o tempo da pena em $1 / 3$, são elas: a) feminicídio ocorrido durante a gestação ou nos três meses posteriores ao parto; b) Feminicídio contra menor de 14 anos de idade, maior de 60 anos de idade ou pessoa com deficiência; c) Feminicídio na presença de descendente ou ascendente da vítima (artigo 121, $\S 7^{\circ}$., do Código Penal brasileiro).

Feminicídio é algo que vai além da misoginia, criando um clima de terror que gera a perseguição e morte da mulher a partir de agressões físicas e psicológicas dos mais variados tipos, como abuso físico e verbal, estupro, tortura, escravidão sexual, espancamentos, assédio sexual, mutilação genital e cirurgias ginecológicas desnecessárias, proibição do aborto e da contracepção, cirurgias cosméticas, negação da alimentação, maternidade e esterilização forçadas. Constitui uma categoria sociológica nitidamente distinguível e que tem adquirido especificidade normativa (SEMÍRAMIS, 2011, Revista Fórum).

Devemos observar, todavia, que não é pelo fato de uma mulher figurar como sujeito passivo do delito tipificado no artigo 121 do Código Penal que já estará caracterizado o delito qualificado, ou seja, o feminicídio. Para que reste configurada a qualificadora, nos termos do § 2-A, do artigo 121 da Lei Penal, o crime deverá ser praticado por razões de condição de sexo feminino, que efetivamente ocorrerá quando envolver: I - violência doméstica e familiar; II - menosprezo ou discriminação à condição de mulher.

Merece ser salientado, por oportuno, que o feminicídio, em sendo uma das modalidades de homicídio qualificado, pode ser praticado por qualquer pessoa, seja ela do sexo masculino, ou mesmo do sexo feminino. Assim, não existe óbice à aplicação da qualificadora se, numa relação homoafetiva feminina, uma das parceiras, vivendo em um contexto de unidade doméstica, vier a causar a morte de sua companheira (GRECO, 2017, p. 69).

\section{Estatísticas do CNJ}

Um ano depois de sancionada a Lei do Feminicídio (Lei $\mathrm{n}^{\circ}$. 13.104/2015), as atenções concentram-se para o interior do país, onde 
são marcados expressivos índices de homicídios de mulheres e um número pífio de unidades judiciárias especializadas. Segundo o Relatório Justiça em Números de 2015, do Conselho Nacional de Justiça, das 91 varas exclusivas de violência doméstica, a maioria se encontra nas capitais - o que faz que a realidade nas cidades de médio porte seja impactante.

A pesquisa Mapa da Violência 2015, uma compilação de dados oficiais divulgados pela Organização Mundial da Saúde (OMS), Organização Pan-Americana de Saúde (OPAS), ONU Mulheres e Ministério das Mulheres, da Igualdade Racial e dos Direitos Humanos, revelou que as taxas de feminicídio nas cidades de até 100 mil habitantes são as mais altas. Barcelos, município do interior do Amazonas, é um dos exemplos mais significativos. Com apenas 20 mil habitantes, está em primeiro lugar no ranking de feminicídio do país. Em dois anos, foram registrados 25 casos de homicídios femininos naquela localidade.

A constatação da geografia da violência indica para um de seus maiores desafios: a interiorização de seu combate.

A mudança na penalização dos assassinatos femininos para homicídio qualificado determinou penalidades mais rígidas e inafiançáveis aos casos que envolverem violência doméstica e familiar ou menosprezo e discriminação à condição de mulher.

A Lei $n^{\circ}$. 13.104/2015, que entrou em vigor em 10 de março, incluiu o assassinato de mulheres na lista de crimes hediondos (Lei $\mathrm{n}^{\circ}$. 8.072/1990). O regime inicial de cumprimento da pena é o fechado e somente pode haver progressão para um regime menos rigoroso quando for cumprido no mínimo $2 / 5$ da pena, se o criminoso for primário, e de $3 / 5$ se for reincidente.

No Rio de Janeiro, dos 16 homens presos condenados pela Lei do Feminicídio, apenas um tem origem na capital. Dos crimes, quinze ocorreram em municípios do interior, como Rio das Ostras, Seropédica e Nova Iguaçu. O dado reforça a constatação feita pela pesquisa Mapa da Violência 2015, de que o perigo está nas cidades de médio porte, como em Natividade. Com cerca de 15 mil habitantes, o único juizado (não especializado) da cidade que fica no noroeste fluminense recebe, 
ao menos, um caso de violência contra a mulher por dia (Conselho Nacional de Justiça).

O Brasil só perde para El Salvador, Colômbia, Guatemala e Federação Russa em número de casos de assassinato de mulheres (Conselho Nacional de Justiça). Por aqui, muitos desses casos ocorrem em municípios de pequeno porte, onde não há delegacias da mulher. Na ausência de uma delegacia especializada, as vítimas de violência recorrem às delegacias tradicionais, onde há menos preparo dos policiais para lidar com casos dessa envergadura (Conselho Nacional de Justiça).

Em comparação com países desenvolvidos, o Brasil mata 48 vezes mais mulheres que o Reino Unido, 24 vezes mais que a Dinamarca e 16 vezes mais que o Japão ou Escócia (Conselho Nacional de Justiça). De acordo com os dados do Mapa da Violência 2015, a taxa de assassinato de mulheres negras aumentou 54\% em dez anos, passando de 1.864 (em 2003 ) para 2.875 (2013). O número de crimes contra mulheres brancas, em contrapartida, caiu $10 \%$ no mesmo período, de 1.747 para 1.576 (Conselho Nacional de Justiça).

\section{ConsideraÇões Finais}

A expressão máxima da violência contra a mulher é o óbito. As mortes de mulheres decorrentes de conflitos de gênero, ou seja, pelo fato de serem mulheres, são denominadas feminicídios ou femicídio. Estes são geralmente perpetrados por homens, principalmente parceiros ou ex-parceiros, e decorrem de situações de abusos no domicílio, ameaças ou intimidação, violência sexual, ou situações nas quais a mulher tem menos poder ou menos recursos do que o homem.

O feminicídio pode ser definido como um crime de ódio contra as mulheres, caracterizado por circunstâncias específicas em que o pertencimento da mulher ao sexo feminino é central na prática do delito. Entre essas circunstâncias estão incluídos os assassinatos em contexto de violência doméstica e os crimes que envolvem violência sexual, mutilações - especialmente do rosto, seios e genitais -, exposição pública do corpo da mulher, tortura etc. Os crimes que caracterizam o feminicí- 
dio reportam, no campo simbólico, à destruição da identidade da vítima e de sua condição de mulher.

A Convenção de Belém do Pará de 1994, à qual o Brasil aderiu em 1995, e reprisada na "Lei Maria da Penha" - é sempre fundamental no esforço desse ideário protetivo. A lei projeta valores no corpo social e não deixa de ser uma força para superar tradições machistas, somando esforços com as metas que procuramos atingir no sentido de proteção e valorização da mulher.

A categoria gênero teve um papel fundamental no processo de criação da lei: conferiu complexidade ao processo, uma vez que sedimentou o entendimento das violências para além do campo jurídico. Por meio dela foi possível, enfim, interpretar a prática das violações contra mulheres a partir de uma dinâmica de poder que está pautada em modelos de conduta impostos a homens e mulheres, em todos os momentos de sua vida, e que constituem cotidianamente a ambos.

O comportamento de homens e mulheres em nossa sociedade é pautado na falsa ideia da inferioridade e subordinação da mulher. Assim, a mulher é geralmente mais valorizada quando se dedica inteiramente à família, aos filhos, ao marido, ao cuidado com a casa. Na caminhada dessas falsas ideias, quando ela não segue esse comportamento, está dando margem para reações violentas por parte dos homens. A violência passa a ter um valor positivo, sendo vista como um corretivo que os homens se julgam no direito de aplicar às mulheres, para disciplinar seu comportamento. Como nossa sociedade produz modelos de comportamentos desiguais para homens e mulheres, fica evidente que a violência contra as mulheres faz parte da nossa cultura, de todas as coisas que aprendemos e continuamos a fazer no cotidiano.

\section{REFERÊNCIAS}

AFONSO, J. S. Curso de direito constitucional positivo, 35. ed., rev. e atual. até Emenda Const. n. 68, de 21.12.2011. São Paulo: Malheiros, 2012.

BRASIL. 10 anos da adoção da Convenção Interamericana para Prevenir, Punir e Erradicar a Violência contra a Mulher, Convenção de Belém 
do Pará / Agende Ações em Gênero Cidadania e Desenvolvimento. Brasília: AGENDE, 2004.

BRASIL. 2017. Câmara dos Deputados. http://www2.camara.leg.br/legin/ fed/lei/2015/lei-13104-9-marco-2015-780225-norma-pl.html. Acesso em: 10 abr. 2017.

BRASIL. 2016. Código Penal. Decreto-lei 2.848, de 7 de dezembro de 1940. Disponível em: http://www.planalto.gov.br/ccivil_03/decreto-lei/Del2848 compilado.htm. Acesso em: 30 out. 2016.

BRASIL. 2016. Constituição (1988). Constituição da República Federativa do Brasil. Disponível em: http://www.planalto.gov.br/ccivil_03/constituicao/ constituicaocompilado.htm. Acesso em: 30 out. 2016.

BRASIL. 2016. Conselho Nacional de Justiça. http://www.cnj.jus.br/programas-e-acoes/lei-maria-da-penha/formas-de-violencia. Acesso em: 10 abr. 2017.

BRASIL. 2017. Conselho Nacional de Justiça. http://www.cnj.jus.br/programas-e-acoes/lei-maria-da-penha. Acesso em: 10 abr. 2017.

BRASIL. 2017. Conselho Nacional de Justiça. http://www.cnj.jus.br/noticias/ cnj/79187-magistrados-aprendem-a-reconhecer-perigo-de-vida-em-violencia-domestica. Acesso em: 10 abr. 2017.

BRASI. 2017. Conselho Nacional de Justiça. http://www.cnj.jus.br/noticias/ cnj/77282-aumento-da-pena-para-feminicidio-da-maior-protecao-a-mulher-avalia-conselheira. Acesso em: 10 abr. 2017.

BRASIL. 2016. Senado Federal. http://www12.senado.leg.br/institucional/ datasenado/publicacaodatasenado?id=somente-um-em-cada-quatro-internautas-que-participaram-de-enquete-mostrou-se-a-favor-da-proposta-que-torna-crime-hediondo-o-assassinato-de-mulheres-vitimas-de-violencia-domestica-e-familiar. Acesso em: 10 abr. 2017.

CANOTILHO, J. J. G. Direito constitucional e teoria da constituição, 7. ed., 16 reimp. (Manuais universitários).

CAPANO, E. F. Legislação penal especial / Evandro Fabiani Capano. São Paulo: Revista dos Tribunais, 2015.

GARCÍA-PABLOS DE MOLINA, A. O que é criminologia? / Antonio García-Pablos de Molina; tradução Danilo Cymrot. 1. ed. São Paulo: Revista dos Tribunais, 2013. 
GEBRIM, L. M.; BORGES, P. C. C. Violência de gênero: tipificar ou não o femicídio / feminicídio? Revista Informativa Legislativa. Brasília: n. 202, p. 59-75, 2014.

GRECO, R. Código Penal: comentado / Rogério Greco. 10. ed. Niterói: Impetus, 2017.

. Curso de Direito Penal: parte especial, volume II: introdução à teoria geral da parte especial: crimes contra a pessoa / Rogério Greco, 13. ed. Niterói: Impetus, 2017.

LAGARDE, Marcela y de los Ríos. Del femicidio al feminicidio. Desde el jardín de Freud. Bogotá, 2006.

LOPES, A. G.; MACHADO, I. V.; VENÂNCIO, K. E. A.; LESSA, L. M. Lei Maria da Penha: A importância das políticas públicas de abrigamento no contexto do enfrentamento às violências contra as mulheres. Revista Direitos Humanos e Democracia. Editora Unijuí, n. 7, p. 172-199, 2016.

NUCCI, G. S. Leis penais e processuais penais comentadas / Guilherme de Souza Nucci, 6. ed. rev., reform. e atual. São Paulo: Revista dos Tribunais, 2012 .

PASINATO, W. 2016. "Femicídios" e as mortes de mulheres no Brasil. http://www.scielo.br/scielo.php?script=sci_arttext\&pid =S0104-83332011000200008. Cadernos Pagu. Campinas: n. 37, 2011.

PIOVESAN, F. Temas de Direitos Humanos / Flávia Piovesan, 4. ed. São Paulo: Saraiva, 2010.

TAVARES, A. R. Curso de direito constitucional / André Ramos Tavares, 13. ed. rev. e atual. São Paulo: Saraiva, 2015.

ZACCARIOTTO, J. P. A Polícia Civil e a Defesa dos Direitos Humanos / Pedro José Zaccariotto (org.); Tabajara Novaes Pinto (coord.). São Paulo: ACADEPOL, 2009. 
DAdos do AUTOR

\section{Cleudemir Malheiros Brito Filho}

Professor na União das Faculdades dos Grandes Lagos, UNILAGO - São José do Rio Preto/SP. Brasil. Bacharel em Direito pela Universidade Paulista - UNIP. Pós-Graduação Lato Sensu em Direito Penal e Processual Penal pela Escola Paulista de Direito - EPD (em andamento).

britof1@yahoo.com.br

Submetido em: 21-01-2017

Aceito em: 05-04-2017 